\title{
Paediatric and adult multiple sclerosis: age-related differences and time course of the neuroimmunological response in cerebrospinal fluid*
}

Multiple Sclerosis

I5(I2) 1466-I480

(C) The Author(s) 2009

Reprints and permissions:

sagepub.co.uk/journalsPermissions.nav

DOI: 10.1 I77/I3524585093484I8

msj.sagepub.com

(S)AGE

\author{
H Reiber', M Teut', D Pohl' ${ }^{2,3}$, KM Rostasy ${ }^{2,4}$ and F Hanefeld ${ }^{2}$
}

\begin{abstract}
We investigate common pathophysiology in paediatric and adult multiple sclerosis (MS) by comparison of cerebrospinal fluid (CSF) data. We compared cerebrospinal fluid (CSF) data from eight patient groups with onset of MS at 7 to 29 years $(n=184)$. A new statistics program allows sensitive detection, quantifies the mean amount of intrathecal Ig synthesis in groups based on the $96 \%$ reference range of 4100 non-inflammatory controls, corrects for age-related increase of bloodderived albumin and immunoglobulins in CSF, and presents graphical data interpretation in Reibergrams. Already at onset of MS before puberty ( $\leq 10$ years) the frequency of intrathecal $\operatorname{lgG}$ synthesis (oligoclonal $\lg G$ ) was $100 \%$ like in adults with $98 \%$, but the amount of intrathecal lgG increases twofold during puberty. Intrathecal IgM synthesis is most frequent before and during puberty (in $57-67 \%$ of patients) compared with $41 \%$ in adults. The amount of intrathecal lgM synthesis before puberty is only $30 \%$ of that in adults. IgG and IgM Index are biased evaluations not suitable for characterizing agerelated dynamics. A twofold age-related increase of the albumin quotient, $\mathrm{Q}_{\mathrm{Alb}}$, as a measure of the blood-CSF barrier function, represents normal physiological growth. Cell counts in CSF are low. The pre-puberty gender ratio is about I:I. Intrathecal antibodies against measles, rubella and/or varicella zoster virus are detected in $73 \%$ of patients before puberty compared with $89 \%$ of adults. Individual paediatric patients $(n=17)$, with sequential punctures over $2-5$ years, show constant quantities of intrathecal IgM and specific antibodies. In conclusion, paediatric MS already at first clinical manifestation shows the complete, neuroimmunological data pattern in CSF, i.e. inflammatory signs are not gradually evolving. Paediatric and adult MS differ quantitatively but not qualitatively in neuroimmunological patterns which does not allow for discrimination between 'early' and 'late' onset MS. CSF analysis may help to discriminate between acute and monosymptomatic chronic inflammatory disease already at earliest clinical manifestation.
\end{abstract}

\section{Keywords}

paediatric multiple sclerosis, puberty, cerebrospinal fluid, $\lg G, \lg A$, $\lg M$, intrathecal synthesis, statistics, measles, rubella, varicella zoster, antibody index, $\lg$ index

Date received: 5 May 2009; accepted: 16 August 2009

\section{Introduction}

For years the rediscovery ${ }^{1-3}$ of paediatric multiple sclerosis (MS) nourished the expectation of a better understanding of the pathophysiology of MS. Unfortunately much confusion entered this discussion due to inadequately performed or wrongly interpreted cerebrospinal fluid (CSF) analysis in both children and adults. However, there is an increasing consensus that paediatric MS with manifestations before the age of 16 years and adult $\mathrm{MS}^{3-5}$ are not different diseases.

The intrathecal humoral immune response is the prominent sign observed in CSF of MS patients. ${ }^{5-9}$
'Neurochemistry Laboratory, Department of Neurology, University Göttingen, Germany.

${ }^{2}$ Department of Pediatrics and Pediatric Neurology, University Göttingen, Germany.

${ }^{3}$ Department of Neurology, Children's Hospital of Eastern Ontario, University of Ottawa, Ottawa, Canada.

${ }^{4}$ Division of Pediatric Neurology, Department of Pediatrics, University Innsbruck, Innsbruck, Austria.

*This contribution is dedicated with high regard to the mentor of CSF analysis in Germany, Professor Dr Helmut Bauer (19/4-2008), Göttingen, who motivated our research on paediatric MS as early as in the 1980s.

Corresponding author:

Professor Dr Hansotto Reiber, CSF and Complexity Studies, Muehlenstrasse 3c, D37073 Göttingen, Germany.

Email: ho@horeiber.de 
The predominant IgG class reaction is detected by oligoclonal bands after isoelectric focusing ${ }^{10}$ in $98 \%$ of the adult MS patients. Owing to this high sensitivity the detection of oligoclonal $\mathrm{IgG}$ became an essential part of a qualified laboratory supported diagnosis of MS. ${ }^{11}$ The less-frequent intrathecal IgM class response $(20-50 \%)$ has been investigated ${ }^{5}$ mainly with respect to its predictive value for the course of the disease. ${ }^{12,13}$ The quantification of intrathecal IgG, IgA and IgM became possible due to the well-established and theoretically founded nonlinear reference range for blood-derived proteins in $\mathrm{CSF}^{14,15}$ avoiding incorrect interpretations due to linear $\operatorname{IgG}$ or $\operatorname{IgM}$ index with false-positive and false-negative interpretations in CSF routine diagnosis. ${ }^{6}$ Also the missing compensation for the physiological age-related change of the bloodCSF barrier function, particularly in children, led to a bias in the interpretation of earlier results. With the new statistics software ${ }^{8}$ we correct for this physiological increase of the blood-derived albumin, $\operatorname{IgG}$ and $\operatorname{IgM}$ fractions in CSF.

An extraordinarily frequent intrathecal antibody synthesis against measles, rubella and varicella zoster virus (VZV) was reported as a particular aspect of the humoral immune response in the central nervous system (CNS) of MS patients ${ }^{16-18}$ in both adults and children. In principle, a concomitant polyspecific immune response takes place in all immune reactions in the blood and brain. ${ }^{19}$ This is explained as a part of the immunological network response. The frequency of these particular antibodies against neurotropic viruses, also called MRZ-antibody reaction, ${ }^{16}$ is remarkably high in MS and also in autoimmune diseases with involvement of the CNS such as systemic lupus erythematosus or Sjögren's syndrome, ${ }^{20}$ but not in other acute or chronic inflammatory diseases such as HSV encephalitis, neurotuberculosis or neurosyphilis. ${ }^{21}$ This makes the MRZ-antibody reaction more specific albeit less sensitive than detection of oligoclonal $\mathrm{IgG}$, which in contrast can be found in any acute and chronic inflammatory process of the brain. This polyspecific immune response has a low intensity (smaller amount) compared with the antibody synthesis against a persisting causative antigen, which might be $20-60$-fold stronger in HSV encephalitis, subacute sclerosing encephalitis or the Fuchs heterochromic cyclitis of the eye. ${ }^{19}$ Owing to its diagnostic potential for the detection of monosymptomatic MS at the time of its first manifestation, it seems reasonable to compare this polyspecific antibody response against neurotropic viruses in children and adult MS patients.

The new statistical approaches count the frequencies of intrathecal Ig fractions with higher sensitivities and calculate mean intensities of this synthesis with correction for the physiological variation of the age-related
blood-CSF barrier function. This should allow us to detect more reliably possible age-related differences between the weaker immune response in early-onset MS and the stronger response in late-onset MS.

As important complementary information to the statistical data of groups of patients at the time of disease onset we also report the time course of intrathecally synthesized amounts of immunoglobulins and antibodies in individual paediatric patients who underwent repeated lumbar punctures for diagnostic reasons.

With the sophisticated description of the neuroimmunological response in CSF of paediatric MS patients we aim to improve the differential diagnosis of acute and chronic inflammatory diseases of the CNS in childhood. ${ }^{3,22,23}$

\section{Methods and patients}

\section{Paediatric patients}

All young patients were part of a larger, prospectively studied cohort with suspected MS, first admitted to the Department of Pediatric Neurology, GeorgAugust-University Göttingen, Germany, between 1987 and 2002. The study was approved by the Ethics committee of the Medical Faculty, University Göttingen, Germany.

We report only those patients with a complete set of analytical data: 82 MS patients with a disease manifestation before the age of 16 (54 girls, 28 boys); 17 of these patients had a repeated lumbar puncture.

Basic data collection included gender, age at disease onset, clinical presentation, neuroradiological and CSF findings. Detailed clinical data are summarized elsewhere. ${ }^{24}$ Mean age at MS onset was 12.5 years (range: 4-16 years). The statistically evaluated data represent the analysis of the first 'diagnostic' puncture. In this cohort of paediatric MS patients $(n=135)$ the initial spinal tap was performed during the first attack in 106 patients $(78 \%)$, during the second attack in 26 $(19 \%)$ and during the third attack in $3(2 \%)$ patients. Haemolytic, blood-contaminated or turbid CSF samples were excluded. The age-related gender distribution is reported in Table 2. Cases with onset between 7 and 10 years are interpreted separately as a pre-puberty group.

\section{Serial analytical data}

A subgroup $(n=17)$ of these young patients was punctured two to five times for diagnostic purposes over a period of up to 6 years after manifestation of the disease. The patients had $2-10$ relapses during this time. The serial analysis was performed for intrathecal $\mathrm{IgG}$ and $\operatorname{IgM}$. 
The MRZ antibody analysis (Table 2) was performed in 78 children. A serial antibody analysis was also performed in all 17 children who underwent repeated lumbar punctures.

\section{Adult patients}

The data of adult MS groups originate from a cohort of 267 patients with clinically definite $\mathrm{MS}^{25}$ with a mean age of 36 years and a female-to-male ratio of $1.95: 1$, published earlier. ${ }^{5}$ We report the statistical data of a subgroup with 103 MS patients between 17 and 29 years of age ( 76 women and 27 men). The data of the age-related groups (Table 2) are recalculated with the new statistics software. ${ }^{8}$

\section{Control group}

The control group for CSF data with absence of an intrathecal humoral immune response is constituted from 4100 patients. ${ }^{14}$ These data were obtained from CSF routine analysis in the same laboratory (Neurochemistry Laboratory, Department of Neurology, Georg-August-University, Göttingen). Main exclusion criteria were CSF oligoclonal IgG and an atypical relation in the $\mathrm{Q} \operatorname{IgG} / \mathrm{Q} \operatorname{IgA} / \mathrm{Q} \operatorname{IgM}$ pattern. These data constituted the reference range of the CSF/ serum quotient diagrams. ${ }^{14}$

\section{Protein analysis}

Albumin, $\operatorname{IgG}, \operatorname{IgA}$ and $\operatorname{IgM}$ in CSF and serum were analysed with immunochemical nephelometry, particleamplified for IgA and IgM (Dade Behring Nephelometer Prospec, Marburg, Germany). CSF and diluted serum samples were analysed paired in the same analytical run. Data were recorded online and interpreted numerically and graphically in the integrated CSF report including CSF/serum quotient diagrams (Reibergrams). ${ }^{6}$

\section{Blood-CSF barrier function}

The albumin quotient, $\mathrm{Q}_{\mathrm{Alb}}=\mathrm{Alb}(\mathrm{CSF}) / \mathrm{Alb}$ (ser), as a measure of the individual blood CSF barrier function was interpreted with the age-related reference range, ${ }^{6,7}$ $\mathrm{Q}_{\mathrm{Alb}}=(4+$ age $($ years $) / 15) \times 10^{-3}$. The significance of a barrier dysfunction is calculated on a $10 \%$ and $20 \%$ level above the age-related border of the reference range. ${ }^{8}$

\section{CSF statistics tool}

It is important to understand the basic difference between the diagnostic approach for the single patient and the statistical approach for groups: for diagnostic purposes in routine analysis, the intrathecal synthesis is quantified as the relative intrathecal fraction, $\mathrm{Ig}_{\mathrm{IF}}$, as a percentage of total $\mathrm{Ig}$ in CSF, with reference to $\mathrm{Q}_{\lim }$ (Figure 1), to allow a comparison of different Ig classes response and disease related immunoglobulin patterns ${ }^{6}$ in the single patient.

The absolute amount of intrathecal Ig synthesis, $\mathrm{Ig}_{\text {loc }}$, in milligrams per litre CSF is preferred for a quantitative description of the time course of intrathecal synthesis of a single immunoglobulin. In the case of diagnostic interpretations the reference for detection of the intrathecally synthesized amounts $\left(\mathrm{Ig}_{\mathrm{IF}}\right.$ or $\left.\operatorname{Ig}_{\mathrm{loc}}\right)$ is the upper borderline of the reference range, $\mathrm{Q}_{\mathrm{lim}}$ $\left(=\mathrm{Q}_{\text {mean }}+3 \mathrm{SD}\right.$ (standard deviations) $)$ or $99 \%$ range for highest specificity.

For a comparison of groups we usually compare means with their SD. Therefore, the calculation of intrathecal amounts (preferentially quantity of locally synthesized $\mathrm{Ig}$ fraction, $\mathrm{Ig}_{\mathrm{loc}}$, in milligrams per litre $\mathrm{CSF}$ ) refers to the mean of the reference range, $\mathrm{Q}_{\text {mean }}$, expressed as $\operatorname{Ig}_{\text {loc }}$ (mean) or $\operatorname{Ig}_{\text {loc }}(\mathrm{m})$ in Tables $1-3$.

Table 1 presents two representative calculation examples for diagnostic and statistical approaches with $\mathrm{Q}_{\mathrm{lim}}$ and $\mathrm{Q}_{\text {mean }}$ related values: for a 9-year-old MS patient with $\mathrm{Q}_{\mathrm{Alb}}=2.8 \times 10^{-3}$ and a 30 -year-old MS patient with $\mathrm{Q}_{\mathrm{Alb}}=5.3 \times 10^{-3}$. Both patients have different amounts of intrathecally synthesized $\mathrm{IgG}$ $\left(\mathrm{IgG}_{\mathrm{loc}}\right)$, but due to their different blood-derived IgG fractions ( $\left.\mathrm{IgG}(\mathrm{CSF})-\mathrm{IgG}_{\mathrm{loc}}\right)$, they have similar relative intrathecal fractions $\left(\mathrm{Ig}_{\mathrm{IF}}\right)$. This demonstrates why for comparison of groups the $\operatorname{Ig}_{\mathrm{loc}}(\mathrm{m})$ values must be preferred.

Subsequently the frequency of intrathecal synthesis in a group of patients counts the numbers of cases with $\mathrm{QIg}>\mathrm{Q}_{\text {mean }}+2 \mathrm{SD} \quad(96 \%$ range $)$ instead of $\mathrm{QIg}>\mathrm{Q}_{\text {lim }}=\mathrm{Q}_{\text {mean }}+3 \mathrm{SD}$ (99\% range). The different frequencies of intrathecal synthesis for both decision borders of the reference range are calculated and reported for MS groups in Table 2.

The new CSF statistics approach is based on two observations: ${ }^{14}$

(1) In the control group the distribution (variation) of the immunoglobulins ( $\mathrm{QIgG}, \mathrm{QIgA}, \mathrm{Q} \operatorname{IgM})$ at a certain albumin CSF/serum quotient, $\mathrm{Q}_{\mathrm{Alb}}$, is symmetrical (Gaussian) around $\mathrm{Q}_{\text {mean }}$.

(2) The mean coefficient of variation in the control group with $\mathrm{CV}(\mathrm{Q} \operatorname{IgG})=15 \%, \mathrm{CV}(\mathrm{QIgA})=23 \%$ and $\mathrm{CV}(\mathrm{Q} \operatorname{IgM})=60 \%$ is constant, i.e. valid for all $\mathrm{Q}_{\mathrm{Alb}}$ values, or independent of CSF flow rate. The $\mathrm{Q}_{\text {mean }}+2 \mathrm{SD}$ border is calculated with $\left[\left(\mathrm{Q}_{\mathrm{lim}}\right.\right.$ $\left.-\mathrm{Q}_{\text {mean }}\right)=3 \mathrm{SD}$ ] for the individual $\mathrm{Q}_{\text {Alb }}$ value of the single patient, reported in the knowledge base of the statistics tool. ${ }^{8}$ 


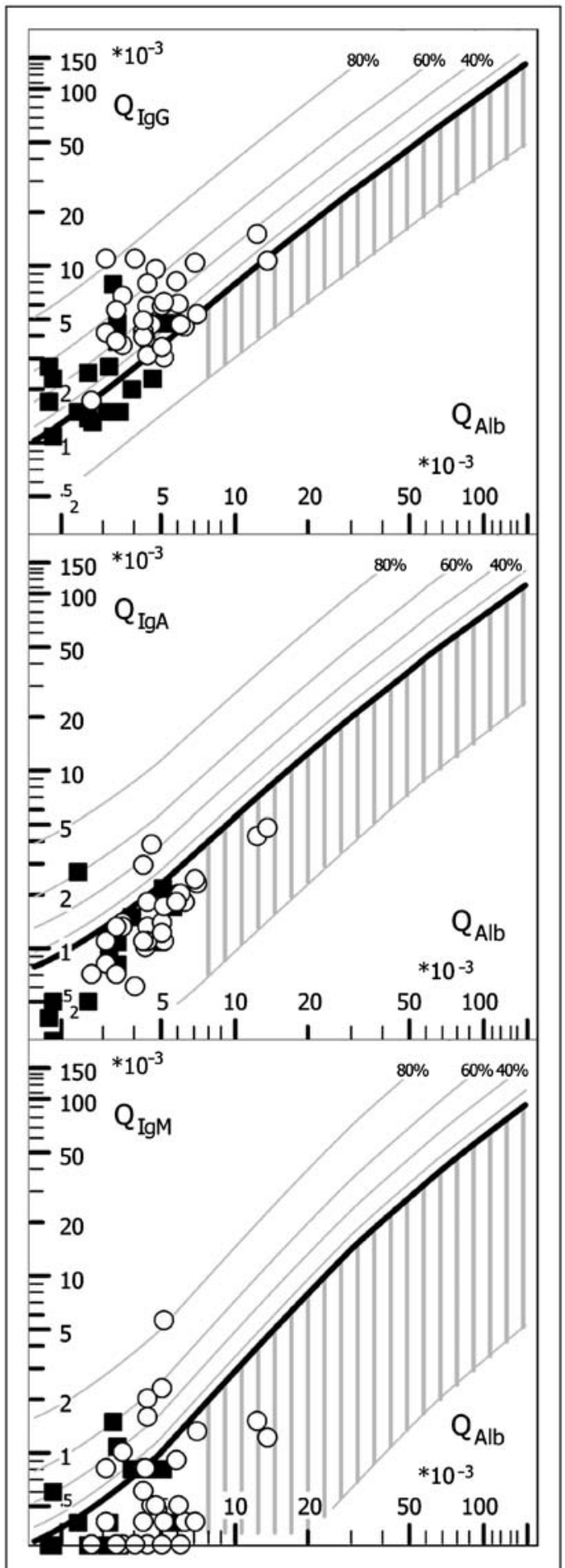

Figure I. Comparison of CSF data from MS patients in the age groups of 7-II years (squares) and 28-29 years (open circles) in CSF/ serum quotient diagrams (Reibergrams). ${ }^{6,7}$ These diagrams are double logarithmic graphs for the reference range of blood-derived immunoglobulins in CSF, constructed from 4100 non-inflammatory control patients. ${ }^{14}$ This is the range between the thick upper hyperbolic border line $\left(Q_{\text {lim }}\right)$ and the lower hyperbolic borderline $\left(Q_{\text {low }}\right)$, including $99 \%$ of the controls or $Q_{\text {mean }} \pm 3 S D$.The range with vertical lines is the range of increased albumin quotients, $Q_{\text {Alb }}$, due to a blood-CSF barrier dysfunction. Values above the upper limit of the reference range, $Q_{\text {lim }}$, are regarded as an intrathecal synthesis, the extent of which is read from the dashed hyperbolic lines presenting the intrathecal fractions, Ig IF with $20 \%, 40 \%, 60 \%$ or $80 \%$ of total CSF Ig concentration. The intrathecally synthesized amount of $\operatorname{lgG}$, IgA or $\lg M$ is calculated for diagnostic purposes with reference to $\mathrm{Q}_{\lim }$ and for statistics of the whole group with

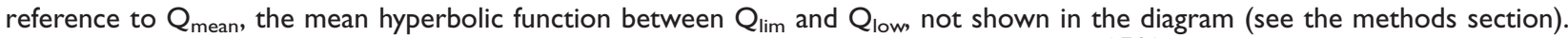
The CSF/serum quotient diagrams are explained in detail with applications in the literature. ${ }^{6,7,26}$ Corresponding statistics of the both MS groups are shown in Table 2. The diagram is created with the new CSF statistics tool. ${ }^{8}$ 
Table I. Calculation examples in diagnostic and statistical CSF data interpretation with $\mathrm{Q}_{\text {lim }}$ or $\mathrm{Q}_{\text {mean }}$ related evaluation. Two MS patients with $\mathrm{Q}_{\text {Alb }}$ values representative for the mean of their age group (e.g. in Figure I)

\begin{tabular}{|c|c|c|c|c|c|c|c|c|c|c|}
\hline \multicolumn{4}{|c|}{ Analytical data } & \multicolumn{4}{|c|}{ Diagnostic interpretation } & \multicolumn{3}{|c|}{ Statistical evaluation } \\
\hline $\begin{array}{l}\text { Age } \\
\text { (years) }\end{array}$ & $\begin{array}{l}Q_{\text {Alb }} \\
\times 10^{3}\end{array}$ & $\begin{array}{l}\lg G_{C S F} \\
(m g / l)\end{array}$ & $\begin{array}{l}\text { QlgG } \\
\times 10^{3}\end{array}$ & $\begin{array}{l}Q_{\lim } \\
\times 10^{3}\end{array}$ & $\begin{array}{l}\mathrm{Ig}_{\mathrm{loc}} \\
(\mathrm{mg} / \mathrm{l})\end{array}$ & $\begin{array}{l}\lg G_{I F} \\
(\%)\end{array}$ & $\lg G$ index & $\begin{array}{l}Q_{\text {mean }} \\
\times 10^{3}\end{array}$ & $\begin{array}{l}\lg _{\mathrm{loc}}(\mathrm{m}) \\
(\mathrm{mg} / \mathrm{l})\end{array}$ & $\begin{array}{l}\lg \mathrm{G}_{\mathrm{IF}}(\mathrm{m}) \\
(\%)\end{array}$ \\
\hline 9 & 2.8 & 28 & 3.0 & 1.76 & 11.8 & 42.2 & I.I & 1.19 & I7.1 & 61.0 \\
\hline 30 & 5.3 & 70 & 6.4 & 3.73 & 29.3 & 41.9 & 1.2 & 2.5 & 42.7 & 61.0 \\
\hline
\end{tabular}

Ig $G_{C S F}$ concentration of IgG in CSF; $Q_{\text {lim }}$, upper border of the reference range; $Q_{\text {mean }}$, mean of the reference range; $I g G_{l o c}$, amount of locally synthesized, intrathecal $\lg G$ in CSF; $\lg G_{I F}$ relative amount of intrathecal $\lg G$ in CSF with reference to $Q_{\lim }$, zero synthesis; $\lg G_{\text {loc }}(m)$, amount of intrathecal $\lg \mathrm{G}$ in CSF; $\lg \mathrm{G}_{\mathrm{IF}}(\mathrm{m})$, relative amount of intrathecal $\lg \mathrm{G}$ in CSF with reference to $\mathrm{Q}_{\text {mean }}$, zero synthesis in statistics approach; $\lg \mathrm{G}$ index, QlgG/QAlb.

Table 2. Age-related CSF data in MS at the time of the first 'diagnostic' puncture of a patient

\begin{tabular}{|c|c|c|c|c|c|c|c|c|c|}
\hline \multicolumn{10}{|c|}{ Age-related data (means of groups) } \\
\hline \multicolumn{10}{|l|}{ Parameter } \\
\hline Age-Range & units & $\begin{array}{l}7- \\
\text { II }\end{array}$ & $\begin{array}{l}12- \\
13\end{array}$ & 14 & $\begin{array}{l}15- \\
16\end{array}$ & $\begin{array}{l}17- \\
21\end{array}$ & $\begin{array}{l}22- \\
24\end{array}$ & $\begin{array}{l}25- \\
27\end{array}$ & $\begin{array}{l}28- \\
29\end{array}$ \\
\hline Total $n$ & years & 18 & 29 & 17 & 18 & 25 & 23 & 26 & 29 \\
\hline $\mathbf{Q}_{\text {Alb }}$ & $\times 10^{3}$ & 3.2 & 3.8 & 4.0 & 3.9 & 4.8 & 5.0 & 4.7 & 5.3 \\
\hline Dysf. ( $\geq 10 \%)$ & & $1 / 18$ & $3 / 29$ & $1 / 17$ & $2 / 18$ & $8 / 25$ & $4 / 23$ & $3 / 26$ & $5 / 29$ \\
\hline OCB & $\%$ & 89 & 86 & 100 & 100 & 95 & 100 & 92 & 100 \\
\hline $\lg \mathbf{G}_{\text {loc }}(\mathrm{m})$ & $\mathrm{mg} / \mathrm{l}$ & 13.6 & 22.5 & 24.7 & 29.3 & 27.3 & 24.2 & 34.4 & 40.1 \\
\hline IgG-Fr (2SD) & $\%$ & 67 & 71 & 82 & 83 & 76 & 70 & 81 & 97 \\
\hline IgG-Fr (3SD) & $\%$ & 61 & 68 & 71 & 78 & 68 & 65 & 77 & 79 \\
\hline IgG index & Med & 0.74 & 0.74 & 0.81 & 0.76 & 0.96 & 0.70 & 1.0 & 1.0 \\
\hline $\operatorname{Ig} \mathbf{A}_{\text {loc }}(\mathrm{m})$ & $\mathrm{mg} / \mathrm{l}$ & 0.31 & 0.36 & 0.39 & 0.18 & 0.45 & 0.3 & 0.5 & 0.5 \\
\hline IgA-Fr (2SD) & $\%$ & 29 & 15 & 19 & 12 & 16 & 9 & 12 & 17 \\
\hline $\operatorname{IgM}_{\text {loc }}(m)$ & $\mathrm{mg} / \mathrm{l}$ & 0.48 & 1.25 & 1.16 & 0.97 & 0.88 & 1.22 & 0.8 & 0.8 \\
\hline IgM-Fr (2SD) & $\%$ & 56 & 56 & 50 & 59 & 48 & 44 & 46 & 41 \\
\hline IgM-Fr (3SD) & $\%$ & 31 & 48 & 38 & 47 & 24 & 39 & 31 & 21 \\
\hline Gender & $m: f$ & $8: 10$ & $10: 19$ & $6: 11$ & $4: 14$ & $5: 20$ & $6: 17$ & $10: 16$ & $6: 23$ \\
\hline Cell count median & $\mathrm{c} / \mu \mathrm{l}$ & 3 & 10 & 10 & 15 & 20 & 12 & 12 & 12 \\
\hline Cell count range & $c / \mu \mathrm{l}$ & $0-8$ & $\mathrm{I}-78$ & $1-38$ & $0-42$ & $1-96$ & $1-32$ & $0-30$ & $3-44$ \\
\hline$M-A I \geq I .5$ & $\%$ & 75 & 56 & 50 & 62 & 63 & 71 & 64 & 86 \\
\hline $\mathbf{R}-\mathbf{A l} \geq \mathbf{I . 5}$ & $\%$ & 36 & 41 & 21 & 47 & 55 & 41 & 67 & 67 \\
\hline$Z-A I \geq I .5$ & $\%$ & 54 & 61 & 36 & 33 & 38 & 55 & 60 & 63 \\
\hline MRZ pos. & & $12 / 17$ & $19 / 27$ & $8 / 16$ & $11 / 18$ & $17 / 25$ & $20 / 23$ & $22 / 26$ & $28 / 29$ \\
\hline
\end{tabular}

Statistics are calculated with a new CSF statistics tool. ${ }^{8}$ The distribution of patients in diagrams is compared in Figure I for the 7-II years and the 2829 years groups. Igloc $(m), Q_{\text {mean }}$ related intrathecal Ig synthesis. IgG - fraction (2SD) frequency of cases with $Q \lg >Q_{\text {mean }}+2 S D$. IgG - fraction (3SD) frequency of cases with $\mathrm{Qlg}>\mathrm{Q}_{\text {mean }}+3 \mathrm{SD}\left(=\mathrm{Q}_{\mathrm{lim}}\right)$ (see Table I). Frequency of increased antibody index for measles $(\mathrm{M}-\mathrm{Al})$, rubella $(\mathrm{R}-\mathrm{Al})$ and Varicella zoster (Z-Al) antibodies in the fraction of patients with detectable values. MRZ reaction is taken as positive for any patient with one to three of the intrathecally synthesized MRZ antibodies. The borders of the age groups were selected to get somehow groups of similar size. In addition to the age group 7-II years we report the data of a definitely prepuberty subgroup ( $\leq 10$ years) in Table 3.

In this way the CSF Statistics tool provides access to a large non-inflammatory control group for everybody who analyses $\mathrm{CSF} /$ serum quotients according to the state of the art as method-independent values. ${ }^{26}$
All calculations of means and SD for $\mathrm{Q}_{\text {Alb }}$ and $\operatorname{Ig}_{\text {loc }}(\mathrm{m})$ in groups of patients were performed with this tool. ${ }^{8}$ It provides all data needed to perform a $t$-test to show that there is not a significant difference 
Table 3. Prepuberty and postpuberty differences in CSF of MS patients

\begin{tabular}{llll}
\hline Age range & years & $7-10$ & $15-16$ \\
$Q_{\text {Alb }}$ & $\times 10^{3}$ & 2.8 & 3.9 \\
OCB & $\%$ & 100 & 100 \\
IgG $_{\text {loc }}(\mathrm{m})$ & $\mathrm{mg} / \mathrm{l}$ & 14.1 & 29.3 \\
IgG-Fr (>2SD) & $\%$ & 70 & 83 \\
IgM loc (m) & $\mathrm{mg} / \mathrm{l}$ & 0.3 & 1.0 \\
IgM-Fr (>2SD) & $\%$ & 67 & 59 \\
IgM-Fr (>3SD) & $\%$ & 33 & 47 \\
Gender & $\mathrm{m:f}$ & $1: 0.7$ & $1: 3.5$ \\
Cell count median & $\mathrm{c} / \mu \mathrm{l}$ & 3 & 15 \\
M-AI & & $80 \%$ & $61 \%$ \\
R-AI & & $25 \%$ & $45 \%$ \\
Z-AI & & $50 \%$ & $40 \%$ \\
MRZ positive & & $75 \%$ & $66 \%$ \\
\hline
\end{tabular}

For abbreviations, see the legend of Table 2. Mean of group data. The prepuberty age group is restricted to an age $\leq 10$ years to avoid an overlap and bias possible in the group $\leq \mathrm{II}$ years in Table 2 .

between a patient group and the control group (null hypothesis), possible where both groups have a Gaussian distribution. ${ }^{27}$ Groups with intrathecal synthesis which usually have no Gaussian distribution of data need another usual program to calculate the significance of differences. The software also closes the gap in CSF diagnostics enabling the researcher to process data from Excel tables of patients' data into pdf files with Reibergrams (such as Figures 1-4).

The formulae are as follows (all functions can be calculated by the CSF Statistics Tool [8] from patients $\mathrm{CSF}$ and serum concentrations):

$\mathrm{IgG}_{\mathrm{Loc}}=\left(\mathrm{QIg}_{\mathrm{G}}-\mathrm{Q}_{\mathrm{Lim}}\right) \bullet \operatorname{IgG}($ ser $)$ and $\operatorname{Ig}_{\text {loc }}(\mathrm{m})$ $=\left(\mathrm{Q} I g-\mathrm{Q}_{\text {mean }}(\mathrm{Ig})\right)$ - Ig serum $(\mathrm{mg} / \mathrm{l}) \mathrm{IgG}_{\mathrm{IF}}=$ $\left(\mathrm{IgG}_{\mathrm{Loc}} / \mathrm{IgG}_{\mathrm{CSF}}\right) \bullet 100[\%]$ or $\operatorname{IgG}_{\mathrm{IF}}=\left(1-\mathrm{Q}_{\mathrm{Lim}} / \mathrm{Q}_{\mathrm{IgG}}\right)$ - $100[\%]$. $\mathrm{Q}_{\text {Lim }}$ and $\mathrm{Q}_{\text {mean }}\left(=\mathrm{a} / \mathrm{b}\left(\mathrm{Q}_{\mathrm{Alb}}{ }^{2}+\mathrm{b}^{2}\right)^{0.5}-\mathrm{c}\right)$ are calculated with the following values of the variables $\mathrm{a} / \mathrm{b}, \mathrm{b}^{2}, \mathrm{c}: \mathrm{Q}_{\mathrm{Lim}}(\operatorname{IgG})=\left(0,93\left[\mathrm{Q}_{\mathrm{Alb}}{ }^{2}+6\right]^{0.5}-1,7\right) \times$ $10^{-3}$ and $\mathrm{Q}_{\text {mean }}(\operatorname{IgG})=\left(0.65\left[\mathrm{Q}_{\mathrm{Alb}}{ }^{2}+8\right]^{0.5}-1.4\right) \times$ $10^{-3}$ or for IgM class: $\mathrm{Q}_{\mathrm{Lim}}(\mathrm{IgM})=\left(0.67\left[\mathrm{Q}_{\mathrm{Alb}}{ }^{2}+\right.\right.$ $\left.120]^{0.5}-7.1\right) \times 10^{-3}$ and $\mathrm{Q}_{\text {mean }}(\operatorname{IgM})=\left(0.33\left[\mathrm{Q}_{\mathrm{Alb}^{2}}{ }^{2}\right.\right.$ $\left.+306]^{0.5}-5,7\right) \times 10^{-3}[14]$.

\section{Oligoclonal $\lg G$}

Detection of oligoclonal $\operatorname{IgG}$ was performed with $10 \mu \mathrm{l}$ unconcentrated CSF and serum (prediluted to a similar IgG concentration) by immunoblot (NCA foil ECL RPN303D, GE healthcare, Freiburg, Germany) after isoelectric focusing on in-house agarose gels $\left(\mathrm{pH}_{3}-\right.$ 10). The quality is assessed by participation in the CSF survey of INSTAND, Dusseldorf, Germany. The results were expressed as five different types as recommended by a European and an international expert group. ${ }^{10,11}$ A typical performance from our laboratory is shown in a figure of Freedman et al. ${ }^{11}$

\section{Antibody index}

The intrathecal synthesis of $\operatorname{IgG}$ class antibodies of measles (M), varicella zoster (Z), rubella $(\mathrm{R})$ and herpes simplex $(\mathrm{H})$ was analysed using an enzymelinked immunosorbent assay (ELISA) technique (Enzygnost, Siemens (Behring), Marburg Germany) and interpreted as antibody index, AI [18], calculated by $\mathrm{AI}=\left[\mathrm{Q}_{\text {spec }} / \mathrm{Q}_{\mathrm{IgG}}\right]$ or with correction (in the case of $\left.\mathrm{Q}_{\mathrm{IgG}}>\mathrm{Q}_{\text {lim }}\right)$ by $\mathrm{AI}=\left[\mathrm{Q}_{\text {spec }} / \mathrm{Q}_{\text {lim }}\right]$ with reference to the $\mathrm{Q}_{\text {lim. }}$. Diluted CSF $(1: 15)$ and serum $(1: 3000)$ samples are analysed paired in the same analytical run with a standard curve, to calculate from arbitrary concentration units the specific CSF/serum antibody quotient, $\mathrm{Q}_{\text {spec}}$.

The reference range of normal $\mathrm{AI}=1.0 \pm 0.3$ and the clinically defined cut-off for pathologically increased AI values $\mathrm{AI} \geq 1.5$ were detected earlier. ${ }^{18}$

For diagnosis of a 'chronic' inflammatory process in CNS, combinations of MR, MZ or RZ have the highest plausibility. ${ }^{5}$ For statistics the MRZ antibody reaction was counted as positive if one, two or three of the MRZ antibodies were synthesized intrathecally.

For detection of a change in the individual intrathecal antibody reactions in the course of the disease in a single patient, instead of AI values we used the relative concentrations of intrathecal antibody (AB) in CSF, $\mathrm{AB}_{\text {loc }}(\mathrm{m})$, a value calculated with analogy to the $\operatorname{IgG}_{\text {loc }}(\mathrm{m})$ : $\mathrm{Q}_{\text {spec }}$ was calculated retrospectively from AI 


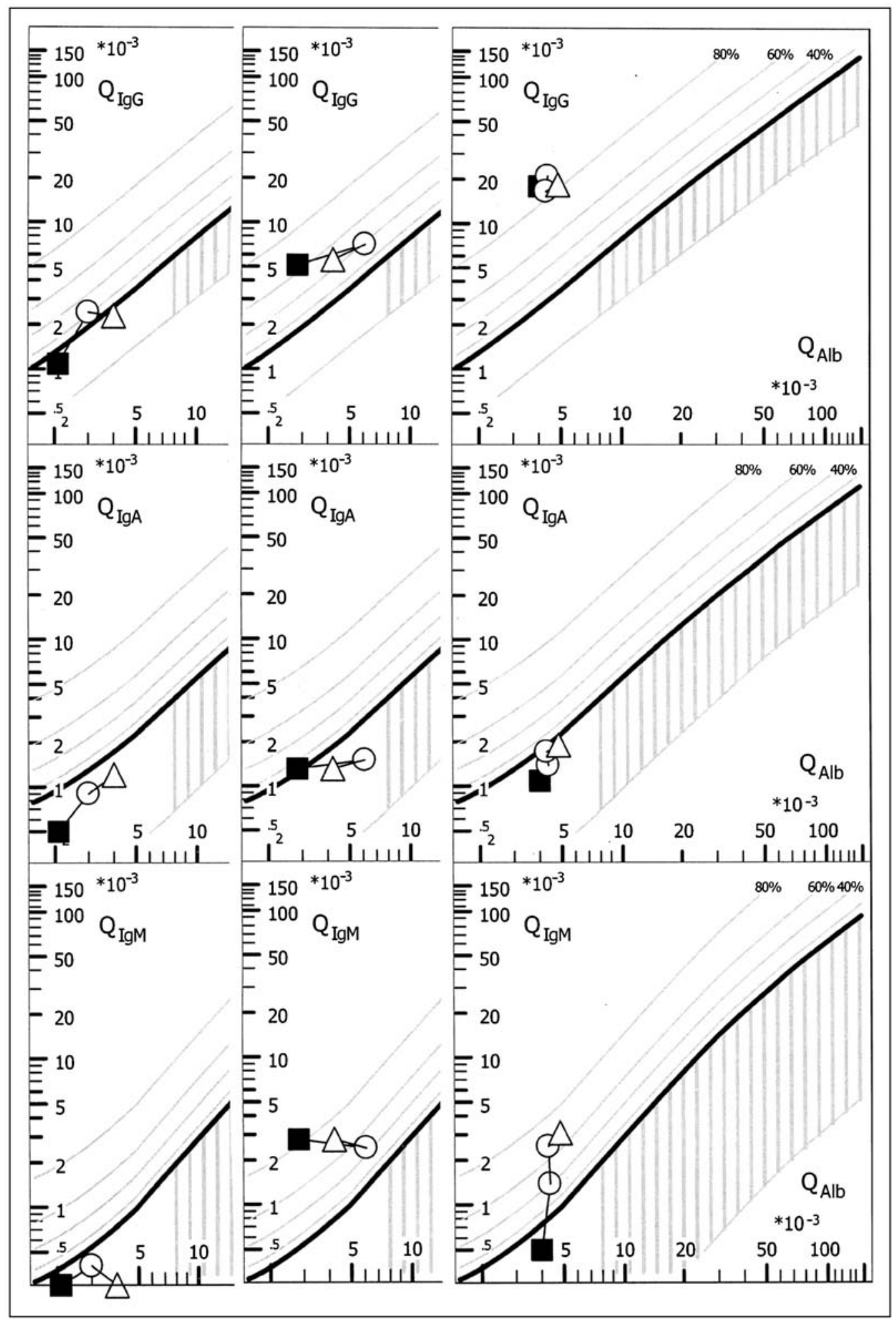

Figure 2. Dynamics of intrathecal $\lg G, \lg A$ and $\lg M$ synthesis in individual patients. The first 'diagnostic' puncture is indicated by a square; the last puncture by a triangle in the diagrams created with the CSF statistics tool. ${ }^{8}$ The left diagram is from a patient with first exacerbation at age of 12 years followed by five relapses in 5 years (CSF punctures at I2, I3.5 and I7.5 years). The middle diagram is from a patient with first clinical symptoms and CSF puncture at age of 13.5 years followed by seven relapses in the next 5 years (punctures at 13.5, 17 and 18.5 years of age). The right diagram is from a patient with first clinical symptoms and CSF puncture at age of $\mathbf{1} 6.5$ years. The clinical course in this patient was of the rare chronic progressive type. Samples were obtained at 2, 3 and 3.3 years after the first puncture. 


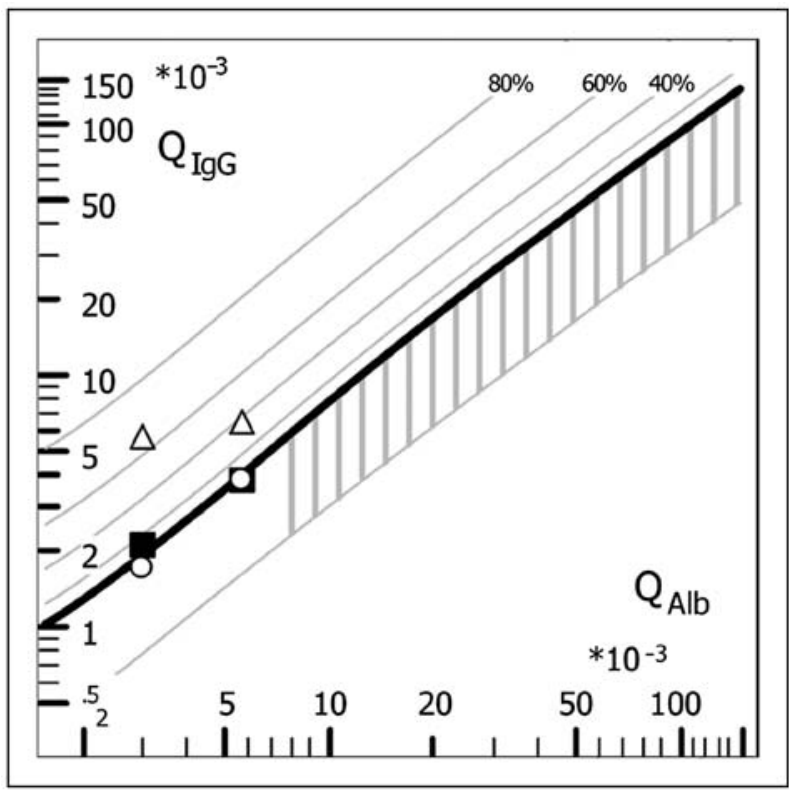

Figure 3. Two antibody quotients in the course of the disease between 14.5 and 15.5 years of age. Triangle, VZV $\mathrm{Q}_{\text {spec }}$; open circles, rubella $Q_{\text {spec }}$; square, $Q_{\text {lgG }}$. Graph created with $C S F$ statistics tool. ${ }^{8}$

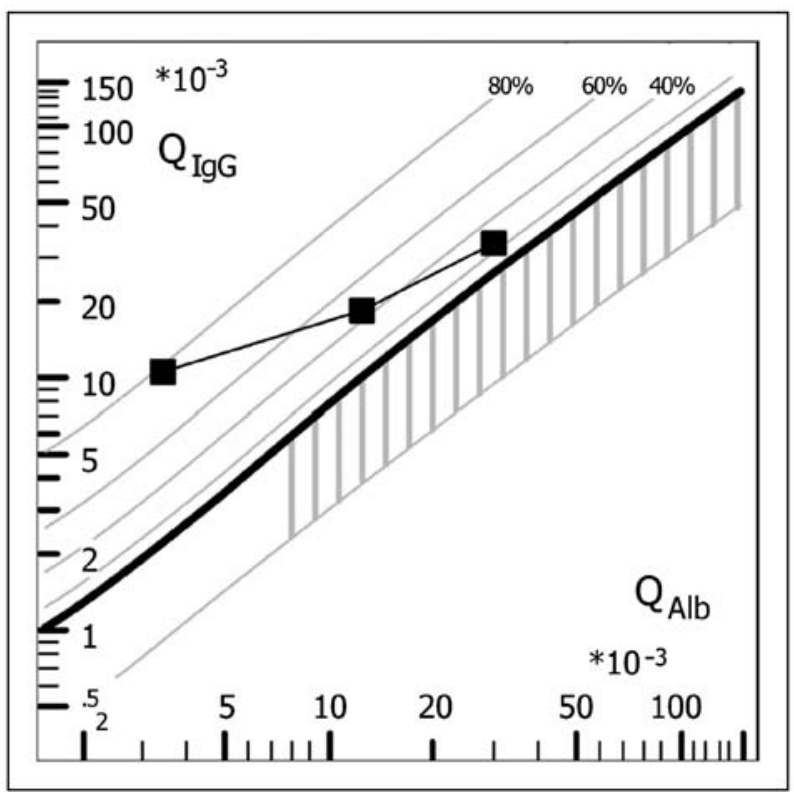

Figure 4. Biased Interpretations with IgG index. Changing IgG index (3.I to I.5 to I.2) and relative intrathecal fractions $\left(\operatorname{lgG}_{\mathrm{IF}}=75 \%\right.$ to $45 \%$ to $25 \%$ ) with increasing QAlb (3.4 to 12.6 to $30 \times 10^{-3}$ ) but constant amount of intrathecal $\operatorname{lgG}$ synthesis $\left(\lg G_{\text {loc }}=75 \mathrm{mg} / \mathrm{l}\right)$ at all three times of investigation. See also Tables I and 2. Graph created with CSF statistics tool. ${ }^{8}$ with $\mathrm{Q}_{\operatorname{IgG}}$ or $\mathrm{Q}_{\lim }(\mathrm{IgG})$ and $\mathrm{Q}_{\text {spec }}$ inserted into the calculation formula for $\mathrm{IgG}_{\mathrm{loc}}(\mathrm{m})$ instead of $\mathrm{Q}_{\mathrm{IgG}}$. The result is a concentration for the intrathecally synthesized antibody in CSF, e.g. $\mathrm{VZV}_{\text {loc }}(\mathrm{m})$ in Table 5, in arbitrary units $(\mathrm{U} / \mathrm{ml})$ exceeding the mean of the reference range $\left[\left(\mathrm{Q}_{\text {spec }}-\mathrm{Q}_{\text {mean }}\right) \times \mathrm{IgGser}\right]$. This retrospective calculation is relevant only for comparison of data from a single antibody species in the same patient. For detection of absolute values of $\mathrm{AB}_{\text {loc }}$ we need antibody serum concentrations, Abser, instead of IgGser. ${ }^{5,28}$

\section{Results}

\section{Blood-CSF barrier function}

The mean albumin quotient, as a measure of the individual blood-CSF barrier function, increases with increasing age in MS patients from $\mathrm{Q}_{\mathrm{Alb}}=3.2 \times 10^{-3}$ (7-11 years) to $\mathrm{Q}_{\mathrm{Alb}}=5.3 \times 10^{-3}(28-29$ years; see Table 2 and Figure 1) corresponding to $3.1-4.6 \times 10^{-3}$ in age-matched normal controls. The frequency of blood-CSF barrier dysfunction was similar in all age groups (Table 2) with a slight tendency to higher frequencies in older age.

\section{Intrathecal IgG synthesis}

Frequencies of intrathecal $\operatorname{IgG}$ synthesis, detected as CSF restricted oligoclonal bands (OCBs), were similar in all age groups studied (Table 2). Already in the youngest pre-puberty age group ( $\leq 10$ years), all 10 cases investigated $(100 \%)$ had oligoclonal IgG in CSF (Table 3). The variation between the groups (Table 2) is mainly due to the small numbers. To see that the low frequency of OCBs in the 7-11 years group is not due to an age-related trend, we evaluated the subgroup $7-10$ years, a definitely pre-puberty age group, separately in Figure 3. In the interpretation by quantitative intrathecal fractions ( $\operatorname{IgG}-\operatorname{Fr}(>2 \mathrm{SD})$ in Table 2) the frequencies for $\mathrm{Q}_{\mathrm{IgG}}>\mathrm{Q}_{\text {mean }}+2 \mathrm{SD}(67-97 \%)$ matches this result of OCBs better than for the diagnostically relevant decision border $\mathrm{Q}_{\mathrm{IgG}}>\mathrm{Q}_{\mathrm{lim}}\left(=\mathrm{Q}_{\text {mean }}+3 \mathrm{SD}\right)$ (IgG-Fr( $>3 \mathrm{SD})$ in Table 2): instead of a mean frequency of $72 \%$ of the adults we now obtain a mean frequency of $82 \%$ and instead of the mean frequency of $69 \%$ of the total group of paediatric patients we obtain $75 \%$ (Table 4 ).

The mean amount of $\operatorname{IgG}$ in $\mathrm{CSF}(\mathrm{mg} / \mathrm{l})$, i.e. the mean intensity of intrathecal $\mathrm{IgG}$ synthesis is larger at older age. The increase of mean $\operatorname{IgG}_{\mathrm{loc}}(\mathrm{m})$ compared with the mean of the control group is significant in all groups $(p<0.01)$ as well as the difference between the pre-puberty and postpuberty groups with ages $7-10$ and 15-16 (Table 3 ). 
Table 4. Comparison of frequencies (percentage of the group) of intrathecal $\lg G, \lg A$ and $\lg M$ synthesis in MS detected with reference to $Q_{\lim }(=3 S D)\left(99 \%\right.$ reference range) and $Q_{\text {mean }}+2 S D(=2 S D)(96 \%$ reference range)

\begin{tabular}{llllll}
\hline & \multicolumn{2}{c}{ Adult MS patients } & & \multicolumn{2}{c}{ All paediatric MS patients ( $\leq 16$ years $)$} \\
\cline { 2 - 3 } & $3 S D^{1}$ & $2 S D^{2}$ & & $3 S D^{3}$ & $2 S D$ \\
\hline $\lg G$ & 72 & $\mathbf{8 2}$ & & 69 & $\mathbf{7 5}$ \\
$\lg A$ & 9 & $\mathbf{1 4}$ & & 6 & 17 \\
$\lg M$ & 20 & $\mathbf{4 1}$ & & 36 & $\mathbf{5 5}$ \\
\hline
\end{tabular}

${ }^{1} n=267$ (Reiber et al. $\left.{ }^{5}\right) ;{ }^{2} 17-29$ years $\left(n=103\right.$, this study); ${ }^{3} n=72$ (Pohl et al. $\left.{ }^{26}\right)$.

Table 5. Dynamics of intrathecal $\lg G$ and $\lg M$ with duration of the disease in individual patients

\begin{tabular}{llll}
\hline & \multicolumn{2}{l}{ Individual time course of intrathecal IgG, IgM synthesis } & Increasing \\
\hline & Decreasing & Constant & $6 / 17$ \\
$\operatorname{lgG}_{\text {loc }}(\mathrm{m})$ & $5 / 17$ & $6 / 17$ & $4 / 16$ \\
\hline $\lg M_{\text {loc }}(\mathrm{m})$ & $2 / 16$ & $10 / 16$ & 46
\end{tabular}

The data for the intrathecally synthesized $\lg G$ and $\lg M($ as $\lg \operatorname{loc}(\mathrm{m})$ in $\mathrm{mg} / \mathrm{l})$ come from 17 children with MS and repeated punctures over a period up to 6 years (examples in Figure 2). The data were interpreted according to the tendency between the first diagnostic puncture and the last puncture after $2-6$ years.

IgG index: The more then twofold increase of intrathecal $\mathrm{IgG}$ synthesis in the age between 7 and 29 years is not mirrored by the median of the linear IgG Index (Table 2). This systematic bias explains why an $\mathrm{IgG}$ Index was the source of many wrong interpretations in MS research.

\section{Intrathecal IgM synthesis}

The frequency of intrathecal IgM synthesis (IgM-Fr in Table 2) at the time of first clinical investigation of the MS patients is slightly higher at younger age, observed in $67 \%$ (Table 3) compared with $41 \%$ (Tables 2 and 4 ) of the older patients. These frequency data from 2SD discrimination line are higher than those reported earlier with reference to $\mathrm{Q}_{\lim }$ such as the data in Table 2 with reference to $\mathrm{Q}_{\mathrm{lim}}$. In particular, in young children these frequencies are much higher than those referring to the 3SD borderline (IgM-Fr $=33 \%$ in Table 3). These discrepant frequencies between the 2SD and $3 \mathrm{SD}$ evaluation are mainly in the very young children (Tables 2-4) due to the more sensitive method which is obviously necessary to detect the intrathecal IgM synthesis due to a smaller amount of intrathecal IgM synthesis in young children. The decrease of frequencies of IgM synthesis at the time of first available lumbar puncture from pre-puberty $(67 \%)$ or from total paediatric group (55\%) to the adult group $(41 \%)$ is significant (Table 4).
The mean amount of intrathecal IgM synthesis in prepuberty children $\left(\operatorname{IgM}_{\mathrm{loc}}(\mathrm{m})=0.3 \mathrm{mg} / 1 \mathrm{CSF}\right.$ in Table 3) is much smaller than in the postpuberty MS patients with rather invariant values not depending on age $\left(\mathrm{IgM}_{\mathrm{loc}}(\mathrm{m})=0.8-1.2 \mathrm{mg} / \mathrm{l} \mathrm{CSF}\right.$ in Table 2$)$. From Figure 1 we recognize the much larger variation of the quantity of intrathecal $\operatorname{IgM}$ synthesis between different patients than in $\operatorname{IgG}$ or $\operatorname{IgA}$ synthesis.

\section{Intrathecal IgA synthesis}

The IgA class reaction in paediatric MS (7-16 years) is found more frequently (Tabe 4) with reference to the 2SD border (about 17\%) instead of 6\% with reference to $\mathrm{Q}_{\mathrm{lim}}$, and in adult patients with $14 \%$ versus $9 \%$ reported earlier. ${ }^{29}$ The prepuberty frequencies are higher than the frequencies in the adult patients (Table 2). In the paediatric MS group all of the few patients with an intrathecal IgA synthesis also had an intrathecal IgM synthesis.

\section{Immunoglobulin dynamics in individual patients}

The time course of CSF protein concentrations in some individual patients is shown representatively in Figure 2. In the course of the disease the amounts of intrathecally synthesized immunoglobulins in the 
three examples are either decreasing, constant or increasing. As summarized in Table 5 there is no uniform tendency for the time course of the $\operatorname{IgG}$ or $\operatorname{IgM}$ class response in individual patients, i.e. there is neither an isotype switch from $\operatorname{IgM}$ to $\operatorname{IgG}$ class nor a general correlation of the quantity of humoral immune response with the duration of the disease.

\section{Polyspecific antibody response}

In prepuberty MS patients the frequency of intrathecal synthesis $(\mathrm{AI} \geq 1.5)$ of measles $(75 \%)$ and $\mathrm{VZV}$ (50-54\%) antibodies (Tables 2 and 3 ) is similar to the results in adult MS patients $(78 \%$ and $55 \%$, respectively). ${ }^{5}$ The rubella antibody synthesis was less frequent before puberty (Table 3 ) with $25 \%$ versus $65 \%$ in adults. ${ }^{5}$ The frequency of an antibody synthesis against one to three of the MRZ antibodies with $71-75 \%$ in the prepuberty and about $50-70 \%$ in the postpuberty age (12-16 years) (Tables 2 and 3 ) is somewhat lower than frequencies detected in adults with $68-97 \%$ (17-29 years in Table 2) or $89 \%$ in the large group $(n=177)$ of adult patients (mean age 36 years). ${ }^{5}$ A combination of two or three antibodies (MR, MZ, RZ or MRZ), which allows the early diagnosis of a chronic inflammatory disease was observed in $40 \%$ of the paediatric MS patients compared with $67 \%$ in the adult MS group. ${ }^{5}$

Dynamics of specific antibody synthesis in the CNS of a single patient: We report the time course of the concentration of intrathecal antibodies in CSF during the course of the disease in an individual patient (see the example in Figure 3). All 17 patients investigated had oligoclonal IgG in CSF. On the basis of the quantitative values for the intrathecal antibody synthesis $\left(\mathrm{s} . \mathrm{VZV}_{\mathrm{loc}}(\mathrm{m})\right.$ in Table 6) we evaluated 15 patients which had at least two CSF punctures in a time range up to 6 years analysed for MRZ antibodies. Five of 15 patients had no MRZ antibody reaction, in 10 of 15 patients with paediatric MS one to three of the MRZ antibodies were synthesized intrathecally (Figure 3). In these 10 patients a total of 21 antibody time courses could be followed. Fourteen of 21 remained constant over a time range of $2-5$ years, 6 of 21 had an increase and only one antibody concentration (VZV) decreased over time. However, this was a patient who had at the same time between the first (at 16 years) and fourth lumbar puncture (at 19 years) a fourfold increase of measles antibodies and a constant intrathecal rubella antibody concentration in CSF. In three cases of antibody species the initially normal AI was detected as pathologically increased about 3-4 years after first diagnostic puncture (two cases of rubella and one case of VZV antibodies). All three cases could be interpreted as a current immunization (rubella) or fresh systemic infection (VZV). As a consequence we learn that the amount of the intrathecal polyspecific antibody synthesis remains constant in the single patient and that the antibody pattern did not change with only few exceptions.

The polyspecific intrathecal antibody synthesis in MS shows that, at the earliest studied time of the disease, the complete neuroimmunological pattern already exists and the amount is not decreasing, as would be expected in case of an acute inflammatory disease.

\section{Prepuberty and postpuberty differences}

In Table 3 we report data of the subgroup ( $\leq 10$ years) of the 7-11-year-old patients to avoid any bias by an eventually early onset of puberty in some paediatric patients. The main differences between patients $\leq 10$ years and the group with patients aged 15-16 years are summarized in Table 3:

- Gender ratio. The prepuberty ratio of male and female patients is $1: 1$ changing after puberty to about $1: 2$, supporting earlier reports.

Table 6. Quantification of intrathecal antibody concentration for retrospective comparison in the course of the disease in the same patient with several punctures

\begin{tabular}{|c|c|c|c|c|c|c|c|c|}
\hline & $\begin{array}{l}\mathrm{Q}_{\text {Alb }} \\
\times 10^{3}\end{array}$ & $\begin{array}{l}\mathrm{QlgG} \\
\times 10^{3}\end{array}$ & $\begin{array}{l}\lg G \text { Ser } \\
(g / l)\end{array}$ & $\begin{array}{l}\mathrm{Q}_{\lim } \\
\times 10^{3}\end{array}$ & VZV-AI & $\begin{array}{l}Q_{\text {spec }} \\
\times 10^{3}\end{array}$ & $\begin{array}{l}\mathrm{VZV}_{\text {loc }}(\mathrm{m}) \\
\mathrm{U} / \mathrm{L}\end{array}$ & $\begin{array}{l}\lg G_{\mathrm{loc}}(m) \\
(\mathrm{mg} / \mathrm{l})\end{array}$ \\
\hline I. P & 3.0 & 2.1 & 8.1 & 1.90 & 3 & 5.7 & 36 & 6.7 \\
\hline 2. $P$ & 5.7 & 3.8 & 10.8 & 4.07 & 1.7 & 6.5 & 40 & 11.1 \\
\hline
\end{tabular}

The method works on the precondition of only a small change in the antibody/total lgG relation in serum between different punctures. The arbitrary concentrations are calculated like $\operatorname{Igloc}(\mathrm{m})$. The change of the albumin quotient (blood-CSF barrier function) between first and second puncture changes the $A l$ in spite of a rather constant amount of intrathecal VZV synthesis. VZV, varicella zoster virus; $A l$, antibody index; $Q_{\text {spec }}, A B(C S F) /$ $A B(S e r) ; V_{Z} V_{\text {loc }}(m)$, intrathecally synthesized VZV antibodies in CSF (arbitrary concentration units per millilitre), calculated with reference to $Q_{\text {mean }}$; $\lg G_{\text {loc }}(m)$, intrathecally synthesized total $\lg G$ in CSF, calculated with reference to $Q_{\text {mean }}$. 
- Cellular immune response. The median lymphocyte/ monocyte cell count in CSF (Table 3) was lowest in the age group of $7-10$ years $(3 / \mu 1)$, but still in the combined, larger group $(n=26)$ of patients in the age range 7-12 years, the median cell count was lower $(6 / \mu 1)$ than in the adult age group, with medians $>10-20 / \mu 1$.

- $\operatorname{Ig} G$. The frequency of intrathecal $\operatorname{IgG}$ synthesis (OCBs or IgG-Fr (2s)) was consistently high at all ages but the amount of intrathecal $\mathrm{IgG}$ in CSF increases strongly during puberty (Table 3 ) and increases thereafter only slightly with age (IgGloc $(\mathrm{m})$ in Table 2).

- $\operatorname{Ig} M$. The frequency of intrathecal IgM synthesis is highest at disease onset before and during puberty $(57-65 \%)$ and slowly decreases with age afterwards to $41 \%$ of the patients. Most noticeably the amount of intrathecal IgM in CSF at onset in prepuberty is only $30 \%$ (Table 3 ) of the amount at onset after puberty, but remains at the same level of frequency (Table 2) in spite of this threefold higher mean amount.

- MRZ antibodies. The frequency of intrathecal MRZ antibodies is lower at earlier age (12/17 versus $28 / 29$ in Table 2). This has to be considered as an expression of the less intense intrathecal IgG class response (IgGloc(m) in Table 2) with a lesser detectability of the MRZ response. ${ }^{5}$

\section{Discussion}

\section{Blood-CSF barrier function: albumin quotients}

There are two explanations for the age-related increase of mean albumin concentration in CSF of children. It is a normal physiological function depending on the agerelated decrease of CSF production rate, i.e. reduced CSF flow rate. ${ }^{14}$ In addition, in the growing child and adolescent, the increasing distance between ventricles and lumbar location of CSF puncture contributes to the increase of protein concentrations in lumbar CSF, as the flow distance along the subarachnoid space becomes longer with body growth, which allows more blood-derived proteins to diffuse into CSF along the prolonged flow path. This is the reason why with the increase of albumin concentration, $\mathrm{Q}_{\mathrm{Alb}}$, the bloodderived fractions of $\mathrm{IgG}$ and $\operatorname{IgM}$ also increase in CSF (Table 1 and Figure 1). An advantage of the applied new software ${ }^{8}$ is the ability to compensate for this possible bias in the calculation of intrathecally synthesized fractions of $\operatorname{IgG}$ and $\operatorname{IgM}$ in CSF (see, for example, in Table 1).

The slightly higher mean albumin quotients in MS compared to the age-matched controls $\left(5.3 \times 10^{-3}\right.$ versus $4.6 \times 10^{-3}$ ) is a consequence of some cases with a moderate blood-CSF barrier dysfunction in the MS group. By exclusion of these cases with barrier dysfunction we obtain in the MS group the same mean as the controls $\left(4.6 \times 10^{-3}\right)$. The almost twofold increase of $\mathrm{Q}_{\mathrm{Alb}}$ in MS patients between 7 and 29 years is therefore predominantly a consequence of the normal physiological age-related increase of $\mathrm{Q}_{\mathrm{Alb}}$. In paediatric MS the number of cases with a blood-CSF barrier dysfunction (Table 2) was slightly lower compared with adults $(8-18 \%)$.

\section{Humoral immune response in CSF}

The qualitative analysis of OCBs allows for the detection of a small fraction as low as $0.5-1 \%$ of oligoclonal IgG within the total blood-derived IgG fraction in CSF. In comparison, up to $100 \%$ increase is necessary in the quantitative evaluation of the intrathecal fraction to obtains a value which is significantly above the statistically defined reference range [26]. Correspondingly the clinical sensitivity for detection of an inflammatory process in adult MS is $98 \%$ for oligoclonal $\mathrm{IgG}$ compared to $72 \%$ $\left(\mathrm{Q}_{\mathrm{IgG}}>\mathrm{Q}_{\mathrm{lim}}\right)$ or now $82 \% \quad\left(\mathrm{Q}_{\mathrm{IgG}}>\mathrm{Q}_{\text {mean }}+2 \mathrm{SD}\right)$ with the quantitative method (Table 4). So OCB, as the most sensitive method, allows an analysis unbiased by calculation with empirical reference values. Nevertheless the quantitative analysis cannot be omitted in CSF analysis for detection of disease-related immunoglobulin patterns, ${ }^{6,7}$ and for calculation of the AI for specific antibodies.

In the sequential analysis of individual patients, recorded up to 5 years, we did not find any changes in the OCB pattern, as expected from many earlier reports. The search for the pathophysiological meaning of this rather stable immune response gained new relevance since we recognized its local variability in the individual patient by comparison of CSF and aqueous humour of the eye of the same MS patient. ${ }^{30}$

For the detection of intrathecal IgM and IgA class response, there is no such direct method available with the equivalent quality and sensitivity of oligoclonal IgG. The detection of 'oligoclonal IgM' as reported by a research group ${ }^{13}$ is biased by the dissoziation of the IgM pentamer into monomers before isoelectrofocusing, which destroys any individual pattern and does not allow a sufficiently qualitative discrimination of blood- and brain-derived IgM. Therefore, we still have to refer to the quantitative method with the statistically defined upper limit of the reference range for the blood-derived fractions in CSF.

For the most sensitive detection and statistical interpretation of intrathecal IgG, IgA and IgM synthesis in groups of patients, we refer now to $\mathrm{Q}_{\text {mean }}+2 \mathrm{SD}$ instead of $\mathrm{Q}_{\text {lim }}\left(=\mathrm{Q}_{\text {mean }}+3 \mathrm{SD}\right) .{ }^{26}$ Instead of the 
diagnostically more specific but less sensitive reference range, including $99 \%$ of the non-inflammatory controls $(n=4100)$, we introduce the reference for the more sensitive $96 \%$ range (Table 2) which approaches, but does not reach, the clinical sensitivity of the oligoclonal bands in MS. This improved sensitivity for $\operatorname{IgG}_{\mathrm{loc}}$ is not a replacement of oligoclonal $\mathrm{IgG}$ analysis, but demonstrates the improved reliability for $\operatorname{IgA}$ and IgM group analysis (Table 2).

This higher sensitivity is needed as demonstrated in particular for the frequency of intrathecal IgM synthesis in MS: former reports ${ }^{5}$ found a frequency of $\operatorname{IgM}$ synthesis in $20 \%$ of adults which is now about $41 \%$ (Table 4). In particular, the difference in the prepuberty children is striking (Table 3): instead of a frequency of $33 \%$ with reference to $\mathrm{Q}_{\text {lim }}$ we now detect a frequency of intrathecal $\operatorname{IgM}$ in $67 \%$ of the paediatric patients. The higher sensitivity of this method explains why we report results that appear controversial in comparison with former calculations from the same group of patients. ${ }^{29}$ Consequently, instead of an age-related higher frequency we now report an age-related lower frequency of intrathecal $\operatorname{IgM}$ at later disease onset (Table 2). In contrast to the frequencies of IgM synthesis at time of disease onset, we find from the examples in Figure 2 and the summary in Table 5 that there is no uniform increase or decrease of the immunoglobulin class response during the individual course of the disease: the intrathecal immune response in a single patient remains rather constant at the initial level of intrathecal $\operatorname{IgM}$ synthesis, as reported earlier for the $\mathrm{IgG}$ response too.

The presence or absence of an intrathecal $\operatorname{IgM}$ response in juvenile MS seems to be of prognostic relevance $^{24}$ albeit different from that obtained by the reports based on a qualitative method. ${ }^{13}$

\section{Bias of $\lg G$ and $\lg M$ Index evaluations}

There is particular controversy in the field of MS research which comes from earlier reports comparing IgM synthesis in patient groups with the linear $\operatorname{IgM}$ index. ${ }^{12}$ This evaluation has an inherent bias by not compensating for the age-related increase or change of the serum protein fractions in CSF. This is demonstrated for the median IgG Index values in Table 2 and the corresponding Figure 4. In Figure 4 with a constant amount of intrathecal $\operatorname{IgG}$ synthesis $\left(\operatorname{IgG}_{\mathrm{loc}}(\mathrm{m})=\right.$ $75 \mathrm{mg} / \mathrm{l})$ at different times of CSF punctures the IgG index is decreasing from 3.1 to 1.5 and 1.2. This is simply due to the physiologically increasing $\mathrm{Q}_{\mathrm{Alb}}$. Also, in case of the threefold higher amount of intrathecal $\operatorname{IgG}\left(\operatorname{IgG}_{\mathrm{loc}}(\mathrm{m})\right.$ in Table 1$)$, the $\operatorname{IgG}$ index values remain about the same.
In addition to the earlier report ${ }^{6}$ where we pointed to false positive and false negative interpretations of $\mathrm{IgG}$ concentrations in CSF with the $\operatorname{IgG}$ Index, we now demonstrate also false interpretations with the IgG Index of the dynamics of intrathecal synthesis due to changing $\mathrm{Q}_{\mathrm{Alb}}$. Owing to the stronger hyperbolic curvature the fault is still more prominent with the $\operatorname{IgM}$ Index than that shown for the $\operatorname{IgG}$ index. ${ }^{26}$

These data again support the statement that the linear $\operatorname{IgG}, \operatorname{IgA}$ or $\operatorname{IgM}$ index is obsolete for a reliable detection of intrathecal $\mathrm{IgG}, \mathrm{IgA}$ or $\operatorname{IgM}$ synthesis ${ }^{26}$ in contradiction to the proposal in the McDonald criteria for diagnosis of $\mathrm{MS}^{25}$

\section{Specific antibody synthesis in CNS (MRZ antibodies)}

For more than 40 years the pathophysiological relevance of the intrathecal antibody synthesis in MS has remained part of ongoing discussions about microorganisms causing MS or initiating new exacerbations. ${ }^{31-36}$ These speculations are caused by the frequent misinterpretation of intrathecal antibodies in CSF. The polyspecific antibody synthesis is part of all acute and chronic immune reactions in blood and $\mathrm{CNS}^{26}$ and does not need the persistence of the corresponding antigen. ${ }^{37,38}$

It was our hope that the understanding of the extraordinarily high frequency of the intrathecal MRZ antibody response in MS and autoimmune diseases with involvement of the brain, ${ }^{20}$ could contribute to a better understanding of the neuroimmunological reaction in the development of this type of chronic inflammatory processes.

As a first result in this study we found that there are only minor differences in the frequencies for measles or VZV antibodies at times of early or late onset of MS (Table 2). The lower frequency of rubella antibodies before adolescence might be a consequence of the immunization program varying in different populations. ${ }^{39}$ As a second result we recognized that the intrathecal antibody synthesis remains constant or might increase in intensity during the course of the disease, observed over several years.

To obtain this second result we had to calculate retrospectively the amount of intrathecal antibodies in CSF. This was needed as the AI is a relative value. $^{26}$ This is shown in Table 6 and Figure 3: if with decreasing CSF flow rate $Q_{\text {Alb }}$ and $Q_{\operatorname{IgG}}$ is increased, the AI will decrease even if the same amount of intrathecal VZV antibody, $\mathrm{Z}_{\mathrm{loc}}(\mathrm{m})(\mathrm{U} / \mathrm{L})$, is synthesized.

These data of the polyspecific immune response contribute two aspects to the field: to the diagnosis of chronic inflammatory diseases and to the understanding of the pathophysiological process. 


\section{Diagnostic relevance of $M R Z$ antibodies and oligoclonal $\lg G$}

The presence of a humoral immune response with oligoclonal IgG (100\%), intrathecal IgM $(67 \%)$ and/or a combined MRZ-antibody response $(40 \%)$ offers a strong argument for the differential diagnosis of paediatric MS and low probability for a suggested diagnosis, e.g. of an acute disseminated encephalomyelitis, ${ }^{22,23,40}$ which rarely $(<20 \%)$ presents oligoclonal IgG.

Since the first report about its diagnostic relevance, ${ }^{16}$ it is now confirmed that a simultaneous presence of two or three antibodies (MR, MZ, RZ or MRZ) has a high probability of being an expression of a chronic inflammatory disease of the autoimmune type. ${ }^{20,26}$ This was observed in $40 \%$ of the paediatric MS patients compared with $67 \%$ in the adult MS group. ${ }^{5}$ In spite of its lower frequency in paediatric MS this is a helpful diagnostic tool for detecting the chronic process already at the time of a first clinical manifestation and also in the case of a monosymptomatic appearance. This aspect is underestimated in the international discussion, which focuses primarily on imaging techniques ${ }^{25}$ as a diagnostic tool. The absence of oligoclonal IgG in CSF in an acute neurological childhood disease does not permit the diagnosis of definite or evolving MS, rather the absence points to another disease and needs further diagnostic efforts. CSF analysis therefore represents another strong and probably more powerful tool for differential diagnosis in childhood compared to imaging findings. ${ }^{25}$

\section{Pathophysiological relevance of $M R Z$ antibodies}

The particularly high frequency of the MRZ antibodies among the antibodies against neurotropic viruses is not understood at all. Nevertheless the study of this polyspecific immune response contributes to the understanding of the pathophysiology of MS.

The MRZ antibody reaction in MS does not need the persistence of the microorganism as in acute or chronic inflammatory diseases with a persisting causative antigen (SSPE, ${ }^{41}$ HSV encephalitis, ${ }^{28}$ Fuchs heterochromic cyclitis, ${ }^{19}$ etc.). As the pattern of polyspecific antibodies in CSF is rather stable with the duration of disease, occasionally increasing in amount, and rarely does a new antibody synthesis appear, we can conclude that there is not a permanent invasion of B-cells into the CSF. This is supported by the earlier observation that there is no direct correlation of blood antibody patterns ${ }^{28}$ and CSF antibody patterns. ${ }^{29}$ However, the constancy of the intrathecal response also indicates that the disease is not starting as an acute form showing decline of the intrathecal antibody synthesis as usually observed in acute inflammatory diseases of the brain. ${ }^{26}$ This view is also supported by the other data reported for IgM synthesis and cell count in CSF: an intrathecal IgM fraction in CSF is principally not a sign of acuity. The acute inflammatory disease is recognized by an increased CSF cell count and increased $\mathrm{Q}_{\mathrm{Alb}}$. Both observations are not prominent in young children with MS, whereas the cell count in the group with the earliest onset is low or at least not higher than in later stages (Table 3) as could be expected for acute diseases.

This intrathecal synthesis of specific MRZ antibodies is also seen in aqueous humour of MS patients with an uveitis intermedia or periphlebitis retinae. ${ }^{19}$ With the recent observation that the MRZ antibody response pattern is different in aqueous humour and CSF of the same MS patient ${ }^{30}$ we obtain an important argument for the local variability of the B-cell invasion into the CNS in MS patients. At least it is a further argument against the often-repeated suggestion of a causative role for microorganisms against which this polyspecific immune response is directed. Clinical immunology would benefit from a better understanding of the regulation in the immunological networks as the source of a chronification instead of relying solely on the clonal selection concept.

The finding that the frequency of an antibody synthesis against one to three of the MRZ antibodies with $71-75 \%$ in the prepuberty and $50-70 \%$ in the postpuberty age (Tables 2 and 3) is lower than frequencies detected in adults ${ }^{5}$ with $89 \%$ is, in fact, a consequence of the higher amount of intrathecally synthesized total $\operatorname{IgG}(\operatorname{IgGloc}(\mathrm{m})$ in Table 2). This correlation was extensively studied in adult MS patients. ${ }^{5}$ Again the prepuberty differences present only with a quantitative but not a qualitative difference of the local immune response.

\section{Pathophysiological conclusion}

Manifestation of the neuroimmunological pattern in MS is not a slowly developing process. Already at the earliest clinical manifestation of MS in childhood, the complete neuroimmunological response pattern is unfolded. This aspect has diagnostic relevance and suggests a rethinking of the earliest pathophysiological processes of MS. Paediatric and adult MS differ only quantitatively but not qualitatively in neuroimmunological patterns in CSF which does not allow for discrimination between an 'early' and 'late' onset MS.

\section{Acknowledgement}

We wish to thank the reviewer who carefully read the manuscript and contributed by his critical questions to the significant improvement of the paper. 


\section{References}

1. Duquette P, Murray TJ, Pleines J, et al. Multiple sclerosis in childhood: Clinical profile in 125 patients. $J$ Pediatr 1987; 111: 359-363.

2. Hanefeld F. Characteristics of childhood multiple sclerosis. Int MS J 1994; 1: 91-97.

3. Hanefeld F. Pediatric multiple sclerosis. A short history of a long story. Neurology 2007; 68: 3-6.

4. Bachmann S, Kesselring J. Multiple sclerosis and infectious childhood diseases. Neuroepidemiology 1998; 17: 154-160.

5. Reiber H, Ungefehr ST, Jacobi C. The intrathecal, polyspecific and oligoclonal immune response in multiple sclerosis. Multiple Sclerosis 1998; 4: 111-117.

6. Reiber H, Peter JB. Cerebrospinal fluid analysis-disease-related data patterns and evaluation programs. $J$ Neurol Sci 2001; 184: 101-122.

7. Reiber H. Cerebrospinal fluid-physiology, analysis and interpretation of protein patterns for diagnosis of neurological diseases. Mult Scler 1998; 4: 99-107.

8. Reiber H, Albaum W. Statistical evaluation of intrathecal protein synthesis in $\mathrm{CSF} /$ Serum quotient diagrams. Acta Neuropsychiatrica 2008; 20(Suppl 1): 48-49. (Free download of CSF Statistics Tool from http://www.COMEDcom.de).

9. Sindic CJM, Van Antwerp MP, Goffette S. The intrathecal humoral immune response: laboratory analysis and clinical relevance. Clin Chem Lab Med 2001; 39: 333-340.

10. Andersson M, Alvarez-Cermeño J, Bernardi G, et al. Cerebrospinal fluid in the diagnosis of multiple sclerosis: a consensus report. J Neurol Neurosurg Psychiatr 1994; 57: 897-902.

11. Freedman MS, Thompson EJ, Deisenhammer F, et al. Recommended standard of cerebrospinal fluid analysis in the diagnosis of multiple sclerosis. A consensus statement. Arch Neurol 2005; 62: 865-870.

12. Sharief MK, Thompson EJ. Intrathecal immunoglobulin M synthesis in multiple sclerosis. Brain 1991; 114: 181-195.

13. Villar LM, Masjuan J, Gonzalez-Porque $P$, et al. Intrathecal IgM synthesis is a prognostic factor in Multiple sclerosis. Ann Neurol 2003; 53: 222-226.

14. Reiber H. Flow rate of cerebrospinal fluid (CSF) - a concept common to normal blood-CSF barrier function and to dysfunction in neurological diseases. J Neurol Sci 1994; 122: 189-203.

15. Reiber H. Proteins in cerebrospinal fluid and blood: Barriers, CSF flow rate and source-related dynamics. Restor Neurol Neurosci 2003; 21: 79-96.

16. Felgenhauer K, Schaedlich H, Nekic M, Ackermann R. Cerebrospinal fluid virus antibodies. A diagnostic indicator for multiple sclerosis. J Neurol Sci 1985; 71: 292-299.

17. Sindic CJM, Monteyne P, Laterre E. The intrathecal synthesis of virus specific oligoclonal $\mathrm{IgG}$ in MS. J NeuroImmunol 1994; 46: 75-80.

18. Reiber H, Lange P. Quantification of virus-specific antibodies in cerebrospinal fluid and serum: sensitive and specific detection of antibody synthesis in brain. Clin Chem 1991; 37: 1153-1160.
19. Quentin CD, Reiber H. Fuchs' Heterochromic Cyclitis - rubella virus antibodies and genome in aqueous humor. AJO 2004; 138: 46-54.

20. Graef IT, Henze T, Reiber H. Polyspezifische Immunreaktion im ZNS bei Auto-immunerkrankungen mit ZNS-Beteiligung. Z ärztliche Fortbildung 1994; 88: 587-591.

21. Stachan-Kunstyr R, Wagner D, Wurster U. Occurrence of virus antigenspecific antibodies in neurological diseases. Akt Neurol 1996; 23: 66.

22. Pohl D, Hennemuth I, Kries R, Hanefeld F. Paediatric multiple sclerosis and ADEM in Germany: results of a nationwide survey. Eur J Pediatr 2007; 166: 405-412.

23. Poser CM, Brinar VV. Disseminated encephalomyelitis and multiple sclerosis: two different diseases - a critical review. Acta Neurol Scand 2007; 116: 201-206.

24. Stauch C, Rauchenzauner M, Pohl D, Hanefeld F, Reiber H, Rostásy KM. Intrathecal IgM synthesis in children with multiple sclerosis is associated with a slower progression. Acta Neurol 2009; submitted.

25. McDonald WI, Compston A, Edan G, et al. Recommended diagnostic criteria for multiple sclerosis: Guidelines from the international panel on the diagnosis of multiple sclerosis. Ann Neurol 2001; 50: 121-127.

26. Wildemann B, Reiber H, Oschmann P. Laboratory diagnosis in neurology. Thieme, 2009.

27. Bechter K, Reiber H, Herzog S, Fuchs D, Tumani H, Maxeiner HG. Cerebrospinal fluid analysis in affective and schizophrenic spectrum disorders: Identification of subgroups with immune responses and blood-CSF barrier dysfunction. J Psychiatric Research 2009, in press, doi 10.1016/j.jpsychires.2009.08.008.

28. Jacobi C, Lange P, Reiber H. Quantitation of intrathecal antibodies in cerebrospinal fluid of subacute sclerosing panencephalitis, herpes simplex encephalitis and multiple sclerosis: Discrimination between microorganism-driven and polyspecific immune response. J Neuroimmunol 2007; 187: 139-146.

29. Pohl D, Rostasy K, Reiber H, Hanefeld F. CSF characteristic in early onset multiple sclerosis. Neurology 2004; 63: 1966-1967.

30. Reiber H, Kruse-Sauter H, Quentin CD. Local variability of B-cell dependent immune response in aqueous humor and cerebrospinal fluid of the individual multiple sclerosis patient. J Neuroimmunol 2009; submitted.

31. Adams JM, Imagawa DT. Measles antibodies in multiple sclerosis. Proc Soc Exp Biol Med 1962; 111: 562.

32. Vartdal F, Vandvik B, Norrby E. Viral and bacterial antibody responses in multiple sclerosis. Ann Neurol 1980; 8: 248-255.

33. Bloomer LC, et al. Epstein-Barr-Virus infection and antibody synthesis in patients with multiple sclerosis. Arch Neurol 1983; 40: 406-408.

34. Johnson TJ. The virology of demyelinating disease. Ann Neurol 1994; 36: 54-60.

35. Soldan SS, Jacobson S. Role of viruses in etiology and pathogenesis in multiple sclerosis. Adv Virus Res 2001; 56: 513-551. 
36. Gilden DH, Devlin ME, Burgoon MP, Owens GP. The search for virus in multiple sclerosis brain. Mult Scler 1996; 2: 179-183.

37. Godec MS, Asher DM, Murray RS, et al. Absence of measles, mumps and rubella viral genome sequences from MS brain tissue by polymerase chain reaction. Ann Neurol 1992; 32: 401-404.

38. Rostasy K, Reiber H, Pohl D, et al. Chlamydia pneumoniae in children with MS: Frequency and quantity of intrathecal antibodies. Neurology 2003; 61: $125-128$
39. Robinson-Agramonte M, Reiber H, Cabrera-Gomez JA, Galvizu R. Intrathecal polyspecific immune response to neurotropic viruses in multiple sclerosis: a comparative report from Cuban patients. Acta Neurol Scand 2007; 115: 312-318.

40. Bloomer LC, Salmon VC. Epstein-Barr-Virus infection and antibody synthesis in patients with multiple sclerosis. Arch Neurol 1983; 40: 406-408.

41. Conrad AJ, Chiang EY, Andeen LE, et al. Quantitation of intrathecal measles virus $\mathrm{IgG}$ antibody synthesis rate: subacute sclerosing panencephalitis and multiple sclerosis. J Neuroimmunol 1994; 54: 99-108. 